\title{
REVISIÓN DE LA SUBJETIVIDAD LABORAL FEMENINA EN MÉXICO, DESDE LAS TESIS DE LA PSICODINÁMICA DEL TRABAJO $^{1}$
}

\author{
Revision of female labor subjectivity in Mexico from the Thesis of the \\ Psychodynamics of Labor
}

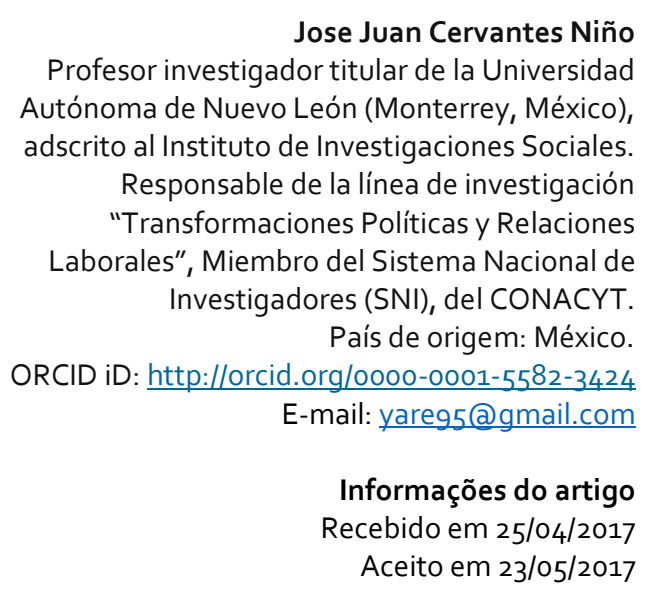

Jose Juan Cervantes Niño

Profesor investigador titular de la Universidad Autónoma de Nuevo León (Monterrey, México), Responsable de la línea de investigación ( Investigadores (SNI), del CONACYT. País de origem: México. E-mail: yare95@gmail.com

Informações do artigo Aceito em 23/05/2017

\begin{abstract}
Resumen
Con la implementación del modelo de desarrollo capitalista neoliberal (8os), la estructura económica global entró en una fase de grandes transformaciones, las cuáles afectaron diversos espacios del desarrollo. En el ámbito de los mercados de trabajo, las alteraciones impactaron las configuraciones típicas del empleo, perjudicando a todos los actores y trastocando con ello sus percepciones laborales; desde diversos niveles de subjetividad. En el ámbito de la subjetividad del trabajo y teniendo como objeto de estudio a las mujeres ocupadas en áreas de limpieza y con base en los supuestos de las tesis de la psicodinámica del trabajo, (en las líneas de las nuevas patologías del trabajo; evasión de la realidad y roles familiares, y simbolismos de defensa), la investigación identifica, analiza y explica una serie de estrategias (simbólicas) que instrumentaron las mismas en el desarrollo de sus actividades. Dichas estrategias tienen como objetivo eludir las repercusiones negativas que los altos niveles de precariedad $y$ desigualdad provocaron en su desarrollo ocupacional, personal y familiar, lo cual al parecer les ayudó a sobrellevar su vida social en una armonía aparente. Asimismo, las acciones factiblemente pueden contribuir a perpetuar y mantener la explotación que tradicionalmente sufre este estrato social.

Palabras clave: Subjetividad laboral. Mujeres.

Psicodinámica. Precariedad. Desigualdad.
\end{abstract}

\section{Introducción}

Con la implementación del modelo de desarrollo capitalista neoliberal (8os), el contexto económico global entró en una fase de grandes transformaciones, las cuáles afectaron todos los ámbitos del desarrollo e impactaron su evolución en determinados contextos (OIT-PSEM, 2015). Estas mutaciones han tenido efectos altamente divergentes,

\footnotetext{
${ }^{1}$ Los resultados que se presentan en este artículo son parte del proyecto de investigación "Informalidad y mercados de trabajo en México 1995-2016: Reinterpretaciones e implicaciones para el desarrollo y crecimiento económico" y del libro "Miradas desde la informalidad laboral: Implicaciones para el mercado de trabajo en México", que inicio en enero 2014 y es apoyado por la Universidad Autónoma de Nuevo León.
} 
incentivando la sincronía de desequilibrios en la forma de generar riqueza, acumularla y redistribuirla; así como la ocurrencia periódica de crisis económicas en el sistema global, incrementando los saldos negativos del proceso globalizador (Beck, 2008; Borón, 2003). En el contexto de los mercados de trabajo, las alteraciones impactaron las configuraciones típicas del empleo (empleo formal y protegido), provocando el incremento de la precariedad y desigualdad en las relaciones laborales, así como la estandarización de ocupaciones atípicas (Sennett, 2000; Bauman, 2005).

En consecuencia, surgen una serie de trabajadores que por sobrevivencia son obligados a alienarse a las ocupaciones atípicas (Sennett, 2000; Bauman, 2005). Estos nuevos trabajadores deben de incrustarse en el mundo laboral en condiciones altamente precarias, por lo cual tienden a instrumentar estrategias de subjetivación del trabajo, para con ello desarrollar en una armonía aparente su actividad y que la misma, no induzca una desestabilización personal y social (Sennett, 2000; Dejours, 2009, 2012 Y 2013). La adaptación se sostiene subjetivamente por concepciones basadas en el estatus, motivación y visión de generar satisfacción (personal) en el desarrollo del empleo o trabajo, lo que al parecer podría tender a perpetuar la estabilidad de explotación del mercado laboral capitalista (Bauman, 2000 y 2005, Dejours, 2009 Y 2012).

En este contexto, el estudio tiene como supuesto el demostrar que la divergencia de las percepciones individuales de los trabajadores sobre sus entornos laborales tienden a subjetivar los alcances de la precariedad y desigualdad, mediante la construcción de simbolismos que atenúan las contradicciones laborales, lo cual a su vez puede perpetuar y aumentar la explotación laboral en actividades específicas en el mercado de trabajo en México. Los objetivos son: identificar la relación de las nuevas patologías con la situación del trabajo; analizar la manera en que el trabajador evade la realidad y logra mantener sus roles familiares y por último, examinar los mecanismos simbólicos de defensa que construyen los trabajadores para evadir el sufrimiento laboral y social que produce sus ocupaciones. El objeto de estudio son mujeres que desarrollan tareas de limpieza (intendencia); en la modalidad de subcontratación en una universidad pública ${ }^{2}$ de México y para recolectar información se aplicaron 15 entrevistas (a profundidad), las que fueron analizadas con las

\footnotetext{
2 La investigación se realizó en la facultad de filosofía y letras de la Universidad Autónoma de Nuevo León (UANL), junio y diciembre de 2015, las entrevistas son anónimas, por lo cual los nombres de las trabajadoras se modifican para los propósitos del estudio.
} 
tesis de la psicodinámica del trabajo (vinculo social y sufrimiento laboral) (Dejours, 2009; 2012).

Para despejar el supuesto, la investigación se desarrolla en las fases siguientes: En la primera se analizan y explican las teorías de la subjetividad y las tesis de la psicodinámica del trabajo; desde su evolución de la psicopatología individual, perspectivas de los vínculos sociales y del sufrimiento laboral, justificando la utilización del enfoque. En la misma parte, se explica la metodología y las líneas de análisis para despejar la hipótesis. En la segunda y con base en las líneas de estudio se exponen los resultados, armonizados con las tesis teóricas. En una última parte, se examinan las implicaciones de las subjetividades ocupacionales en el mercado de trabajo en México. Asimismo, se proponen abordajes de investigaciones por desarrollar, para contribuir a un mayor entendimiento e implicaciones laborales en el corto, mediano y largo plazo.

\section{Supuestos teóricos, analíticos y metodológicos}

Para Sennett (2000) y Beck (2001), la modernidad produce determinadas circunstancias que incentivan el desarrollo de mayores capacidades en los individuos. Esto provoca un incremento en las facultades para interrogar y reflexionar sobre las condiciones de su existencia (reflexividad), con lo cual se amplían las líneas de acción para cuestionar y problematizar las fuentes tradicionales de sentido. Según Lechner (2002), de forma simultánea la sociedad se vuelve más compleja, provocando cambios en los sistemas de creencias y valores de las personas, lo cual influye en la construcción de sus experiencias, moldeando con ello sus en las trayectorias de vida sociales y laborales.

En esta complejidad y construcción de experiencias, el individuo ejecuta decisiones cotidianamente, evaluando opciones y cursos de acción posibles, en diversos ámbitos (Bauman, 2000). Las numerosas identidades tienen ante sí una multiplicidad de oportunidades, riesgos y ambigüedades, mismas que se gestionan reflexivamente en un horizonte donde las normas y las reglas de acción son cada vez más inciertas (Luhmann, 1992; Bauman, 2000). Esto contribuye a que el sujeto forme su propia identidad en medio de múltiples tensiones y contradicciones, esforzándose por negociar, mediar y articular diversas demandas y argumentos a fin de preservar una línea coherente de comportamiento en la sociedad (Beck, 2001, Giddens y Hutton, 2001). 
Estos procesos obliga al individuo a formular subjetividades que alivian las tenciones generadas por la vida cotidiana y del trabajo (Sennett, 2000; Beck, 2001). Por lo tanto, la subjetividad, se debe entender como la capacidad que tiene el sujeto para pensar, negociar, interactuar y dar determinada intencionalidad a una acción. En lo laboral, la expresión de las capacidades va de lo individual a lo colectivo, llevándose a cabo de manera informal y única, para con ello expresar los pensamientos y realizar las acciones respectivas, dependiendo el contexto y el tiempo, en una ocupación y sector económico especifico (tanto en la formalidad como la informalidad) (Burin, 2003; Meler, 2012; Martínez-Labrin y Bivor-Urrutía, 2014).

En este contexto, y con base en los objetivos de la investigación, se analizaron diversos estudios sobre la problemática de la subjetividad, desde sus perspectivas generales y enfatizando las cuestiones relacionadas al mundo del trabajo, así como al aspecto de la situación ocupacional femenina (Garduño y Márquez, 1995; Burin, 1996, 2003, 2007, 2008; Tunal, 2007; Vélez, 2009; Meler, 2012; Rocha y Cruz, 2013; Fernández, 2013; Martínez-Labrin y Bivor-Urrutía, 2014). Las publicaciones abordan la temática desde la psicología y la sociología laboral (principales tendencias del análisis no sólo en el ámbito de América Latina), mostrando fundamentalmente que las interpretaciones y construcciones del individuo (hombre y mujer) sobre la realidad son complejas y difíciles de analizar y explicar, lo cual induce al mantenimiento de concepciones y predisposiones a la actuación subjetiva y alienada, lo cual obstaculiza la búsqueda de solución a las problemáticas (laborales, de género, políticas), pues su visión individual prevalece sobre lo colectivo, aun cuando esta pueda ser calificada como irracional y perjudicial.

En el mismo orden ideas y con el interés de introducir otras tesis de la psicología y sociología laboral en la interpretación de las subjetividades en America Latina, la investigación utiliza los postulados de la psicodinámica del trabajo (PST) de Christophe Dejours y con ello aportar nuevas perspectivas en este campo de estudios (2012; 2013). Estas tesis se han aplicado en las realidades laborales de Europa, no obstante la expansión de la precariedad y desigualdad en todos los ámbitos del trabajo justifican su instrumentación en otros contextos, sin menoscabo de su pertinencia, así como la posible contrastación de los resultados con investigaciones realizadas con tesis teóricas; en contextos similares o diferentes. A continuación se describen las principales líneas de análisis de la psicodinámica. 
Psicodinámica laboral

Con base en las mutaciones estructurales sociales que afectan todo ámbito laboral, la PST $^{3}$ analiza y explica cómo los sujetos coexisten con exigencias autoritarias, en ambientes de alta precariedad y desigualdad que influyen (positiva o negativamente), en sus trayectorias ocupacionales y relaciones sociales (Dejours, 1990; 1998, 1992; 2000; 2012; 2013). Por un lado se sienten presionados, en tanto tienen que ser, al mismo tiempo, eficientes y productivos en el trabajo, exitosos ante la mirada de los otros (familia, amigos) y auténticos en la subjetividad de sus propios sueños y aspiraciones, por lo que tienden a construir una serie de simbolismos de que los auxilian al enfrentar y a sopesar estas dificultades económicas y sociales.

Para Dejours, 2009, 2010, 2013, la organización del trabajo es siempre una organización autoritaria, productora de sufrimiento en el trabajador, pues junto con empobrecerlo, induce la desaparición de los comportamientos libres. Este proceso impone la voluntad del otro, por lo cual el trabajador la percibe ajena a él, pero comprende (con límites cognitivos), que es lo planificado y lo prescripto, en definitiva, es una política de dominación, generadora de sufrimiento. Esto se concibe como una relación social de trabajo, donde se interviene específicamente en la cuestión de decidir la manera de desarrollar la ocupación, sin opción de otro camino (Dejours, 2010 y 2013).

Asimismo, para estas tesis también el trabajo involucra una forma de compromiso del sujeto para enfrentar una tarea enmarcada por restricciones (materiales y sociales) (Dejours, 2009 y 2010). Confrontar esto implica entender que la brecha entre lo prescripto y lo real o efectivo debe ser descubierto cada vez por el trabajador. El proceso que resuelve este desfase está relacionado con la movilización de los impulsos afectivos y cognitivos de la inteligencia. Cognitivos, cuando el trabajador enfrenta lo imprevisto, lo inédito, lo que todavía no conoce ni transforma en rutina y le da una razón afectiva, en razón de atreverse a transgredir y actuar con inteligencia, pero de modo clandestino formando simbolismos para resistir estas dinámicas opresoras (Dejours, 2006, 2012 y 2013).

\footnotetext{
3 La Psicodinámica del trabajo es una corriente francesa (derivada de la psicopatología laboral) que tiene por objetivo realizar un análisis psicodinámico de los procesos intersubjetivos movilizados por las situaciones de trabajo. Se interesa en los procesos intersubjetivos que hacen posible la gestión social de las interpretaciones del trabajo por los sujetos (creadoras de actividades, de saber hacer y de modos operativos nuevos), así como los simbolismos creados para con ello desarrollara sus labores y sus interrelaciones sociales (Dejours, 1998).
} 
Para comprender el funcionamiento (formativo y funcional) de los mecanismos de defensa, los cuales se mueven como resistencias de estas contradicciones del mundo laboral, se postulan seis principios analíticos y operacionales (Dejours, 2009). Los principios son: Mecanismos ideológicos de defensa del trabajo, sufrimiento mental, mecanismos compensatorios de desajustes entre empleo y modelo productivo, funcionalidad del sufrimiento mental y las consecuencias sobre la salud de la situación ocupacional (Dejours, 2012 y 2013).

Estas percepciones se analizan y explican desde la subjetividad, intersubjetividad, sublimación y emancipación, para identificar posibles causalidades que originan la formación de diversas y complejas estrategias producidas por los trabajadores (Dejours, 2006; 2009; 2012 y 2013). Dichas acciones, funcionan como barreras o defensas simbólicas para evitar en mayor medida los efectos negativos de las relaciones laborales desarrolladas en su empleo, las cuales pueden perjudicar su persona (salud), y como se ha mencionado, sus interrelaciones con los entes productivos, relaciones sociales y percepciones de resistencia ante la explotación política, evitando la búsqueda de su emancipación y liberalización total.

En este contexto, para explicar el supuesto del estudio se plantean las siguientes líneas de análisis, las cuales se correlacionan con las derivaciones teóricas señaladas. Las variables que se analizadas son: Nuevas patologías, trabajo como forma de evadir la realidad, trabajo y su rol en las relaciones socio-familiares, mecanismos sicológicos de defensa y la sublimación. Cada clasificación incluye el análisis de casos e inferencias explicativas.

\section{Propuesta metodológica}

Para el levantamiento de información se utilizó la metodología de estudios de caso con entrevistas a profundidad semi-estructuradas (Vela, 2001, Gundermann, 2001; Yin, 2004). En los estudios de caso lo que se pretende es conocer las características y dimensiones del grupo o comunidad estudiado, así como analizar la correlación entre sus elementos y los significados adquiridos y expresados en las interacciones sociales por parte de los actores; en el particular contexto en que tienen lugar, con esto se logra tener una comprensión más profunda del objeto de estudio y de sus relaciones socio-político-económicas.

Con esta perspectiva, se realizaron 15 entrevistas a mujeres empleadas por empresas que proporcionan servicios de limpieza por medio de la subcontratación en la UANL (Clean 
Service y Vizion). A las mujeres, se les solicita contestar una serie de preguntas, explicándoles la finalidad del estudio y con la advertencia que se grabaran las entrevistas. Estas fueron aplicadas entre junio y diciembre del año 2015 , en sus lugares de trabajo de la universidad y duraron en promedio 45 minutos. La entrevista ésta dividida en ocho apartados generales, correlacionados con los objetivos del estudio y con las teorías utilizadas. Los apartados son: Antecedentes familiares, perspectiva escolaridad e inserción laboral, experiencia laboral, beneficios laborales, vivencia socio-familiar-laboral-política, sufrimiento familiar y laboral, convivencia socio-laboral y retrospectiva, así como, prospectiva de desarrollo. La información recabada se examinó utilizando dos instrumentos, el sociológico de casos empíricos y el software Nvivo. Para este estudio sólo se presentan los resultados del primero, mismos que se distribuyeron en las líneas de análisis patologías laborales, búsqueda reconocimiento social, evasión de la realidad y simbolismos de defensa.

\section{Análisis de resultados e implicaciones teóricas e empíricas}

Con base en las 15 entrevistas, el análisis e interpretación de resultados se operacionalizó siguiendo los objetivos y las líneas de investigación mencionadas, así como ejemplificando las explicaciones con extractos de la información textual de algunos de los $\operatorname{casos}^{4}$. Las entrevistadas, tuvieron rangos de edades entre los 35 y los 60 años, con niveles educativos mínimos (mayoritariamente cursaron la primaria y ninguna accedió a una carrera profesional. Las 15 mujeres, se han desempeñado en trabajos de limpieza durante toda su vida laboral, repitiendo el rol de sus madres, quienes se habían dedicaron también a actividades de limpieza en hogares. Algunas de las entrevistadas relataron que sus familias llegaron al estado de Nuevo León, migrando de la zona sur del país. Todas las entrevistadas estuvieron casadas, con hijos y compartieron anécdotas de problemas familiares, relaciones interpersonales fallidas, maltrato, deterioro en la salud y una buena parte de ellas aceptó dificultades para relacionarse socialmente, por lo que se refugiaron en el trabajo como una forma de evadir la realidad.

En este argumento, se desarrollaron las líneas de investigación mencionadas: desde su base conceptual y se ejemplificaron con ejemplos textuales de las entrevistas, en donde

\footnotetext{
4 Por cuestiones éticas, los nombres de los ejemplos de entrevistas son $\mathrm{f}$ as entrevistadas fueron cambiados.
} 
también se incluye un análisis inferencial teórico empírico. Recordando las cuatro son: las nuevas patologías, el trabajo y las relaciones sociales, las formas utilizadas por las mujeres para evadir la realidad, y por último los mecanismos psicológicos de defensa y sublimación.

Nuevas patologías

Las nuevas patologías están correlacionadas con las transformaciones en el trabajo y con los efectos de estas sobre diversos aspectos físicos y emocionales que desarrolla el trabajador en su interrelación socio-laboral (Dejours, 1992). Estas mutaciones laborales al parecer no son de reciente aparición, pero se han detectado mayormente desde los años 80 del siglo anterior, cuando la implantación del modelo de desarrollo neoliberal incrementó los desequilibrios en los mercado laborales; desempleo, desigualdad y precariedad. Se detectó que estas contradicciones aumentaron síntomas relacionados al: Agotamiento, problemas musculo-esqueléticos, lesiones por esfuerzos constantes y repetitivos, desórdenes mentales; adicciones a psicotrópicos; tentativas de suicidio (en el lugar de trabajo y fuera del mismo) y otro padecimientos en menor medida.

No obstante el incremento de estas patologías, se encontró que una cantidad apreciables de trabajadores tendieron a asimilar psíquicamente estos procesos (intra e intersubjetivos) y con ello a disimular sus efectos (Dejours, 2000). El encubrimiento provocó que los padecimientos (aun los físicos) no fueran distinguibles con la sola observación del desarrollo de un determinada actividad y sólo surgieron con la aplicación de entrevistas a profundidad o en grupos focales.

En el contexto del caso de estudio, estas patologías (físicas o mentales), en muchos casos se percibieron que tienen un probable origen en las relaciones sociales y familiares, y las condiciones del trabajo al parecer tendieron a incrementarlas. No obstante y en las perspectivas de Dejours (2000), se detentaron estrategias de subjetivación para ocultar los grados de precariedad laboral y los posibles en las dolencias o conductas relacionadas. Estas patologías provocaron; desde las más graves: intentos de suicidio, hasta las que afectaron físicamente el desarrollo del trabajo y provocaron también dificultades para funcionar socialmente; estrés, cansancio, dolor de cabeza, mal humor. Los ejemplos de estos desordenes se ubicaron en los casos de: 


\section{Caso Leticia:}

¿Enfermedades por trabajo?

En esa fábrica también duré como cinco años, pero yo me salí sola porque ya era mucha la presión, ya era mucha presión/ ahí se arman lo que son la puerta/ las puertas de las lavadoras/y las jaboneras/tonces yo estaba en el área de puertas/ es muy pesado/ya no aguantaba mis brazos/ya no podía dormir/ ah nombre ya dormía así.../ porque yo le decía al supervisor/ Héctor es que ya me cansé, cámbiame de posición/ no, es que tú eres la buena en esto, necesito-que-estés ahí/ y a veces me decían/se van a quedar/y a veces yo me quedaba/y si me pagaban muy bien/sacaba hasta tres mil cuatro mil pesos/ pero si era una friega/ a veces íbamos de día y nos quedábamos de tarde/o iba en la tarde y nos quedábamos de noche/// no/ no / no era una friega/ le dije no sabes que yo ya no voy a trabajar/

¿Padece dolores físicos?

...le dije yo tengo toda la semana con dolor de cabeza/le digo y sabes que no voy a ir a trabajar me siento muy mal...

¿Y cómo se siente, es mucha presión?

Pues yo creo que sí/ por eso a veces me pongo así / con la migraña

A veces si quisiera aventar la toalla y decir / iiya!!/ dos veces intenté/ irme por una puerta que no debería /

Caso Perla:

¿Se siente usted más presionada y cansada?

Símás cansada/.

¿Cómo ha tratado de superar esta situación?

Puesss//.

¿Ha buscado otro trabajo?

Hasta ahorita no/ pero si/ se nos viene el agua hasta el cuello/ pues hay que buscar otro trabajo $/$.

¿Por parte de la empresa no tienen un médico o psicólogo particular?

No. 
¿Considera usted que es necesario?

Pos yo creo que sí/ mucha gente lo necesita/se siente mal, no lo dicen por miedo a perder la chamba

Caso Luz:

¿Cómo se siente usted cuando le sale una situación de emergencia y no tiene con qué pagar?

Uno se siente bien presionada/// y como te digo yo soy/ que me clavo mucho en eso/ antes cuando no/yo no consultaba porque me dolía bastante bien seguido la cabeza/ cuando pienso mucho me empieza a doler la cabeza / pero ahora que me salió que tengo alta presión/ estoy tomando medicamento / ya hace mucho que no me duele la cabeza/ pero eso era lo que me pasaba / agarraba a pensar/y me dolía la cabeza.

Trabajo como forma de evadir la realidad

Aún y cuando el trabajo les pueda induce algunas patologías o en determinados casos amplia las existentes, también le ayuda a los trabajadores a evadir su realidad social, la que en muchos casos tiende a alienarlos y a la marginación social (Dejours, 2009). Desde la perspectiva intersubjetiva, la persona va construyendo una serie de simbolismos en donde puede; y muchas veces logra, olvidarse de sus problemas cotidianos (mayormente relacionados a la familia), y termina otorgándole al lugar de trabajo un simbolismo, con el cual tiende a evadir sus problemas sociales. Finalmente esta evasión, le configura al trabajo una estructura que enmascara sus efectos negativos y los niveles de precariedad prevalecientes en determinadas actividades.

En el contexto del estudio, las preguntas relacionadas a la anterior suposición, provocaron divagaciones divergentes que reflejaron el grado en que se puede evadir la realidad social, justificando beneficios al trabajo altamente subjetivos. Mientras algunas fueron más directas en aceptar su preferencia a permanecer en el trabajo que en sus hogares o en otras relaciones sociales (suegra), en otras son capaces de construir ciertas cualidades de su actividad para justificar su apego al empleo; algunas son objetivas pero otras subjetivas. Al final, estas trabajadoras tienden valorar el peso de su labor más allá de sus relaciones familiares o de otro tipo, por lo cual en muchas ocasiones estas actitudes les provocaron 
problemas para sobrevivir y lograr que su ocupación sea complemente a su rol social y no otro obstáculo. Los ejemplos de este tipo de situación fueron:

Caso María

¿Le gusta su trabajo?

Sí.

¿Por qué?

No sé / pero me gusta más que estar / la verdad me gusta más que de / como se dice/ que estar en la volca*/será que a mí me gusta más el quehacer/me gusta planchar/ me gusta lavar/ nomás no me pongan a lavar los trastes/ eso sí que no me gusta/ pero lo hago /eso es lo que me gusta / me gusta planchar/ me gusta trapear / pues todo.

\section{Caso Betty:}

¿Le gusta su trabajo? ¿Se aburre?

No bueno si me burro* / me burro * estar en mi casa/me burro estar../ bueno nomás en micasa / prefiero trabajar/bueno no en micasa / porque vivo en casa de mi suegra/ si me aburro estar ahí / perooo / digamos que si me gusta / entrear/ porque me encanta trabajar / yyy / no quiero dejar e-trabajo*/ yo nomás por el seguro/ nomás para sacar puntos/ para Infonavit pa que me den casa/ es el único importante que es eso/ y si si me gusta trabajar / si me encanta trabajar / y no me quiero salir / si me gusta/ no perderlo el trabajo/ porque si me gusta trabajar / si ha trabajado en Gamesa / en muchas partes ha trabajado / pero vuelvo a entrar a esta empresa/ me ha cansado de buscar/y/ no no puedo / no puedo/y después entre otra vez de vuelta en este / en Clean Service/ y si si me gusta mucho trabajar/.

¿Cuáles son los mejores momentos de convivencia en su casa?

No poss no/ trabajar/ prefiero trabajar / por eso estoy trabajando para no verla/.

Caso Norma:

¿Le gusta su trabajo?

Sí/ síme gusta/.

¿Por qué?

Posss / poss sí me gusta porque esta tranquilo/ y está al horario que me gusta a mi verdá* / porque a mí me gusta más de día que de tarde/ porque así ya de perdido en 
el día / en el día estoy trabajando/ya en la tarde o nochecita pos ya les echo un ojo a mis hijas/ porque pos tengo dos que son pos todavía menores de eda* / nomas de estarlas checando/ ya la mayor ya no/ porque ya la mayor ya se me casó/ se casó a los diecisiete a los dieciocho/ pero las otras dos ahí las tengo y hay que estarlas checando porque es la hora que andan ( risas) /// que andan en la calle verdá*.

\section{Caso Luz:}

¿Está a gusto en su trabajo?

Uhmm (afirmando) sí.

¿Por qué puede decir qué le gusta el trabajo?

Poes más que nada por el ambiente de trabajo/// y y poooorr el trato que me dan mis jefes/ porque yo soy de las personas que si me sentiría muy incómoda si siento que no me tratan bien.

¿No ha pensando usted en dejar el trabajo?

Bueno... /bueno últimamente porque ya me cuesta la levantada/(risas) pero ya no me hallo en la casa tampoco/ O sea cuando estoy en la casa estoy desesperada y quiero venir a trabajar y luego... nomas las levantadas aquí/.

Trabajo y su rol en las relaciones socio-familiares

En el contexto de las enfermedades relacionadas al trabajo y de la evasión social subjetivada, el efecto sobre las relaciones sociales en casos determinados es altamente perjudicial y tiende a erosionar estas mismas, así como afectar negativamente la formación de las identidades, fundamentalmente, más específicamente en las mujeres (Dejours, 1998 y 2012). Las tesis de la PST infieren que las reacciones de las trabajadoras pueden estar supeditadas a las cuestiones de género y discriminación que sufren por parte del varón, el cual acepta; en principio, su rol de trabajo necesario para sostener el hogar, pero en el transcurso trata de imponer reglas para evitar una mayor libertad, estas trabas perturban la forma en que el trabajo influye en las relaciones sociales, no sólo con el esposo, sino con el resto de la familia y hasta con los amigos.

Como se constató en las entrevistas del estudio, el efecto que provoca el trabajo de la mujer en sus las relaciones sociales se supedita mayoritariamente a la convivencia que 
desarrollo en el hogar y el esposo o persona con que se esté conviviendo, en un determinada vinculo. Las perspectivas tienen un ciclo perverso de cuatro vertientes: Primero, el esposo o pareja, en todos los casos no estaba de acuerdo en que la mujer trabajara; por cuestiones machistas o costumbres socio-culturales. Segundo, la aceptación de no completar con el ingreso masculino obliga a permitir la búsqueda y entrada a laborar; al parecer con una complacencia amplia. Tercero, el machismo surge y se manifiesta en celos y reclamos por la relaciones con sus pares de trabajo, puede terminar en golpes o discriminación psicológica relacionado al descuido de los hijos y de las labores de la casa. Cuarto, junto con estos reclamos, la trabajadora empieza a sufrir y a cargar con la culpa total del descuido familiar y a revalorar el valor de su trabajo. No obstante, en el proceso de evolución del ciclo, las mujeres tienden a construir una serie de simbolismos que les proporcionaron justificaciones para continuar con sus empleos y con todo lo que provoca esta decisión en relación de la convivencia familiar. Estas visiones se ejemplificaron con las siguientes narrativas:

Caso María:

¿En situaciones difíciles se siente usted apoyada?

La verdad no / sentí como queeé / (no se entiende) / sentí como si que le creyó más a ella que a mí.

¿Cómo se siente ante esa falta de apoyo?

Me siento muy mal/ se me / siento que me decepcionó/ este/ me siento mal / por eso traigo eso/.

¿Cómo considera qué es su relación?

Pues hasta ayer la llevábamos bien/nunca/nunca/incluso no nos insultamos/no nos dicimos* nada/pero no me gusta cómo se pone porque/ porque él se pone como loco y empieza a aventar las cosas/ no me dice nada malo / no me insulta/ no me trata de pegar / no/ pero empieza a aventar las cosas/ tonces* eso es lo que no me gusta / nunca/ nunca se pone así/ si acaso los siete años que llevamos juntos / eso es lo mismo que el tiene/dos veces se ha puesto así / pero/. 
Caso Luz:

¿Cuándo y cómo consiguió su primer trabajo?

Yo empecé a trabajar ya.../ Porque mi esposo nunca... nunca... o sea él no/ no, no quería que yo trabajara// empecé a trabajar.. aquí tengo tres años// (SILENCIO) //a ver.. si empecé a trabajar como al año que yo me cambie para mi casa/ a medio año.. ¿Ha habido algún tipo de problema?

Mi esposo siempre ha sido muy celoso / siii// de primero si / este se enojaba porque me saludaban los guardias, nadamás porque saludo y así / esque dice que los guardias son bien..../ pero nada que ver/ pero ellos/ pero también está en uno/ si nada mas así/ pero de primero porque no estaba acostumbrada a que yo trabajara / pero no ya ahorita ya no/

Caso Perla:

¿Antes de que sucediera, esto cómo considera usted que vivían con esos ingresos?

Ahh sínos alcanzaba mucho/ yo con mi dinero lo gastaba/ trabaja como dicen / casi casi / porrrr/ no estar aburrida en la casa/y ahora tengo que trabajar por necesidad/.

¿Su esposo como vio esa decisión la apoyaba?

No/ no le gustaba/ porque dejaba a mis niñas chiquitas/las dejaba con mi suegra/.

¿Tuvo algún tipo de discusión, o pelea por eso?

Sí / porque él no quería que trabajará / él decía que no que él se iba a aliviar/yyy/pos que que yo no iba a tener necesidad de trabajar/ pero yo dije / no ya voy a trabajar porque mis hermanos ya nos mantenían/y tus hijos no comen igual cuando te dan de limosna/ dije no voy a trabajar/.

¿Cómo encontró la forma para equilibrar sus tareas del hogar y su trabajo?

Pos por ejemplo/ el viernes lavaba/lavaba tres veces en la semana en la tarde/ para que no se me juntara/ y hacia el quehacer en las tardes/ y para que el otro día estuviera limpio/ a veces hasta las diez u once horas de la noche me la pasaba lavando / o haciendo quehacer/la comida/ el desayuno/a veces preparaba comida y todo/ porque no estaban impuestos a comer cualquier cosa/ este y tenía que dejarles comida hecha/ a mi esposo la comida/y su lonche/ porque él estaba impuesto a llevar su lonche/y él ya se tuvo que imponer a hacer su almuerzo/ a hacerles a mis hijas su almuerzo/ y ya se tuvo que acostumbrar/ tuvo que adaptarse a que yo tenía que 
trabajar/ me ayudo mucho/ y luego ya después el hacia el lonche de todos/ nos ayudábamos todo/ pero de primero si batallé mucho/ ahora que hago con tanto trabajo en la casa/.

Caso Norma:

¿Qué piensa cuando los hombres dicen qué la mujer sólo es para la casa?

Pos mal/ porque la mujer no es nada más para la casa/también ellas tienen derecho de trabajar/ no de divertirse / no de salirse verdá* / pero de perdido de salir por ahí verda* que las lleven a pasear ///.

Mecanismos psicológicos de defensa y sublimación

Para Dejours (1992), los mecanismos de defensa psicológicos son construidos por los trabajadores, para luchar o controlar las diferentes formas de sufrimiento, transformándolas inconscientemente en una ideología simbólica en torno al trabajo. Asimismo, la instrumentación de estas estrategias de forma permanente, se convierten en una especie de resistencia al cambio, lo que hace que se mantengan la situación de precariedad de los trabajos y la explotación en los mismos, también funcionan como anestesia, ante el sufrimiento, el cual deja de ser percibido conscientemente por los trabajadores y transformándolo en muchas ocasiones en placer (sublimación).

En este orden, el tema de la resignación por parte de las mujeres, en el trabajo, es un elemento clave que sirve para identificar los principales mecanismos que son usados por las ellas para mantener este tipo de trabajos. Por un lado el empleo, es visto por las mujeres entrevistadas como un deber moral, aun y cuando sus salarios sean precarios. En varios casos estas señalaron que solicitaron aumentos salariales a sus empleadores, pues lo que ganaban no les alcanzaba, no obstante la negativa a otorgárseles, las mismas continuaban en esa actividad aduciendo motivaciones contradictorias. Una de las principales alusiones hacía referencia al buen trato del patrón y a que la actividad era tranquila. En este punto, se olvidaban de su reclamo salarial y al parecer una subjetiva comodidad laboral las empujaba a aceptar la precariedad.

La religión es otro ejemplo de mecanismos que es frecuentemente utilizado por las mujeres, para justificar su salario y su trabajo. Durante las entrevistas fue común escuchar 
frases alusivas a un ser divino y por ello las mujeres tienden a aceptar cualquier situación, pues consideran que ese superior tiene el control de las cosas y en donde sus decisiones quedan relegadas a un segundo plano. Las entrevistadas se muestran negativas ante los cambios que puedan hacer en sus vidas y tienden por aceptar la vida tal como está. Este tipo de defensas creadas hacen que se mantenga inconscientemente el empleo y la precarización del mismo.

Otro de los mecanismos que puede observarse en las entrevistas es la transformación del sufrimiento en placer, las mujeres intentan buscar el reconocimiento por medio de su trabajo, como una forma de evadir su complicada situación. Por otra parte, las relaciones que se forman en el trabajo, funcionan como generadores de identidad laboral, por lo que sin importar el tipo o circunstancias del empleo, este se debe de mantener. De acuerdo a la teoría de Dejours, las trabajadoras otorgan a las relaciones establecidas en el trabajo (compañeras de trabajo, relación con sus jefes directos y otros empleados) mayor importancia que el salario que reciben, por lo que en una mayoría de casos esto también puede tender a perpetuar la precariedad laboral. Algunas narrativas representativas de lo anterior son las siguientes:

Caso María:

¿Ha tratado de buscar algún abogado o asesoría?

No / no / de que sirve si a lo mejor yo no voy a poder / yo misma me hago la negativa/ ¿Cuál es su horario de trabajo?

A las siete pero desde las seis de la mañana estoy aquí, salgo de mi casa a las cinco de la mañana / isiempre! / siempre/ siempre me he sacado los primeros lugares en la fábrica / siempre / yo nunca perdí/ me daban premios/ por puntualidad / por asistencia/ siempre/ porque siempre / me decían: que no te quieren en tu casa o que (risas) / sí/ y ¿porque llegas tan temprano?/ pues porque si me gusta avanzarle siempre / siempre/ siempre/ me daban los primeros lugares/

Caso Betty:

¿Está bien con eso que le pagan? ¿Sus amigas y compañeras qué dicen, qué opinan de eso?

Quién sabe/ nunca hablamos de eso/.

¿Le gusta su trabajo? 
Perooo / digamos que si me gusta / porque me encanta trabajar/yyy/ no quiero dejar e-trabajo*/yo nomás por el seguro/nomás para sacar puntos/para Infonavit pa que me den casa/ es el único importante que es eso/ y si si me gusta trabajar / si me encanta trabajar/y no me quiero salir/si me gusta/no perderlo el trabajo/ porque si me gusta trabajar / si he trabajado en Gamesa / en muchas partes ha trabajado / pero vuelvo a entrar a esta empresa/ me ha* cansado de buscar/y/no no puedo / no puedo/y después entre otra vez de vuelta en este / en Clean Service/ y sí sí me gusta mucho trabajar/.

Caso Norma

¿La han desocupado en alguno de sus trabajo?

$\mathrm{Na}$ */siempre he sido yo que me salgo/ahorita nomas que ya me dice que ya aguante aquí (risas).

¿A usted tratado de pedir un aumento?

No/ pos ya/ como quiera ya de perdido pos de eso a nada/ de perdido / tener poquito.

Caso Luz:

Esas pequeñas discusiones que ha tenido con compañeras ¿a qué se deben?

Esqueeee lo que pasa es que no es tanto lo mío / yo soy de las personas que, que no me gusta que sean injustas con las demás entonces si he tenido problemas con las encargadas de las otras compañías... porque tienen...// como te diré...// las mandan muyfeo/y yo siempre he defendido a las otras personas verdá y es por eso que tengo problemas con ella/ o sea no por otra cosa verdad/.

Caso Perla:

¿Está usted satisfecha con el trabajo de la empresa de Clean Service?

Mmmmm/// poes más que nada / por la empresa no/ porque pagan bien poco/ pero aquí en esta oficina/ en la oficina me han ayudado mucho/ y aquí estoy muy satisfecha /.

¿Cómo es la relación con sus patrones?

Pos bien/ muy bien / me han ayudado mucho/ el problema que tuve con mi esposo que te platico/me dieron permiso seis meses/no me dieron de baja ni nada/.

¿Le siguieron pagando?

No/pero me mantuvieron la plaza / y los permisos que tenía que ir a firmar cada mes/ o cada quince días / pero gracias a dios no me echaron pa' fuera/me aguantaron/. 


\section{Conclusiones e implicaciones}

En la argumentación del supuesto de la investigación, se debe de señalar, que desde una visión general se encontraron muchos indicios que demostrarían el mismo; enfatizando, para el caso específico de las actividades de limpieza y con factibilidad de aplicarse en otros ámbitos laborales. Por una parte, los análisis y explicación inferencial muestran la factibilidad de aplicar las tesis de psicodinámica del trabajo de Dejours y con estas identificar una serie de simbolismos que las trabajadoras desarrollan en actividades altamente precarias, lo cual al parecer les ayuda a sobrellevar y subjetivisar los efectos negativos (laborales y sociales) provocados por este tipo de empleos y a desenvolverse en una aparente armonía en su vida social; aun con padecimientos físicos y mentales atribuibles en parte a su entorno laboral.

Aunado a lo anterior, los indicios también podrían indicar que la instrumentación, subjetiva u objetiva, de los simbolismos puede tender a perpetuar las condiciones de precariedad de las ocupaciones de referencia. Esta afirmación puede demostrarse en las acciones que supuestamente realizan las mujeres contra las condiciones laborales negativas (incluido el bajo ingreso) y que terminan siendo contradictorias y difuminándose en una serie de justificaciones de resignación por estar en ese trabajo y hasta en algunos casos muestran satisfacción por el trato recibido (de sus empleadores) y por lo que les aporta a su desarrollo y vida social. En suma, estas inferencias tienden a demostrar que aún en las ocupaciones de mayor precariedad pueden existir una serie de subjetivaciones del trabajo que de alguna ocultan los niveles de la misma y perpetuarían estas condiciones en mercado de trabajo de México.

En este orden y en base a los objetivos del estudio se entiende más integralmente los alcances de las anteriores inferencias:

a) Se logra identificar algunas patologías; físicas y mentales, que pueden ser atribuidas al desarrollo del trabajo y su impacto en las relaciones laborales y familiares, incluso estas provocan tendencias suicidas en casos específicos.

b) Sopesando la precariedad de las ocupaciones, las mismas incentivan una serie de subjetividades que provocan evasiones de la realidad social. Estas evasiones, aunque satisfactorias para el trabajador, tienden a afectar negativamente las relaciones familiares y sociales en diversos grados y con consecuencias para el desarrollo personal. 
c) Por consiguiente, la realidad de la ocupación impulsa el surgimiento de mecanismos de defensa y sublimación, los que actúan sobre la subjetividad del individuo y transforman una realidad de sufrimiento en una situación soportable y en términos objetivos hasta disfrutables y de relajación individual y grupal.

Sin embargo, esta subjetividad laboral de las trabajadoras es sólo una foto de inicial dentro de un proyecto mayor. Proyecto que busca desde las visiones de las tesis alternativas de la informalidad construir la realidad de estos trabajadores (e incluso de muchas labores formales altamente precarias) desde sus propias miradas, es decir, transmitir sus vivencias e interpretarlas a la luz de la modernidad neoliberal dominante, la cual continua fomentando empleos que por necesidad de sobrevivencia se convierten en constructos fomentadores de la explotación laboral. En este sentido, durante el desarrollo de esta investigación, se están explorando otras líneas de análisis relevantes, y que en un estudio futuro serán importantes de tomar en cuenta, para tener una mayor comprensión de las subjetividades en el trabajo, las cuales son:

a) Análisis de las prestaciones y de los salarios y la opinión de las mismas trabajadoras.

b) Riesgos y medios que enfrentan las trabajadoras y los mecanismos creados para enfrentarlos.

c) La sublimación del sufrimiento, en cuanto a temas de control y vigilancia.

d) Explicar la importancia que tiene su ocupación en el reconocimiento personal y social.

e) Insatisfacción del nivel escolar y otras alternativas de trabajo.

f) Contribución al mantenimiento de la explotación y precariedad laboral en México.

\section{Bibliografía}

Bauman, Zigmunt (2000). La modernidad liquida. Fondo de Cultura Económica, Buenos Aires, Argentina.

Bauman, Zigmunt (2005). Vidas desperdiciadas: La modernidad y sus parias. CLACSO, Buenos Aires, Argentina.

Beck, Ulrich (2001). "Vivir nuestra propia vida en un mundo desbocado: Individualismo, globalización y política". En Giddens, Anthony y Hutton, Will. En el límite: La vida en el capitalismo global, Tusquets, Barcelona, España, pp. 233-246 
Beck, Ulrich (2008). Que es la globalización: Falacias del globalismo. Paidos-Iberica, Barcelona, España.

Borón, Atilio (2003). Estado, capitalismo y democracia en América Latina. FLACSO, Buenos Aires, Argentina.

Burin, Mabel (1996). "Género y psicoanálisis: subjetividades femeninas vulnerables". En Burin, Mabel y Dio Bleichmar, Emilce (comp.). Género, Psicoanálisis, Subjetividad. Paidós, Buenos aires, Argentina, pp. 61-99.

Burin, Mabel (2003). "El deseo de poder en la construcción de la subjetividad femenina. El "techo de cristal" en la carrera laboral de las mujeres". En Almudena, Hernando (Comp.). ¿Desean las mujeres el poder?. Minerva, Madrid, España, pp. 33-78.

Burin, Mabel (2007). Trabajo y pareja: Impacto del desempleo y de la globalización en las relaciones entre los géneros. En Guzmán, María y Tena, Olivia (comp.). Reflexiones sobre masculinidades y empleo. CRIM-UNAM, Ciudad de México, México, pp. 89-126.

Burin, Mabel (2008). "Las fronteras de cristal en la carrera laboral de las mujeres: Género, subjetividad y globalización". Anuario de Psicología, vol. 39, número 1, pp. 75-86.

Dejours, Christophe (1990). Trabajo y desgaste mental. Humanitas, Buenos Aires, Argentina.

Dejours, Christophe (1992). Trabajo y desgaste mental: Una contribución a la psicopatología del trabajo. PRONATTE-SECYTE, PIETTE-CONICET, CEIL-CONICET, CREDAL-CENRS, Facultad de Psicología, UBA, Humanitas, Buenos Aires, Argentina.

Dejours, Christophe (1998). Como formular una problemática de la salud en ergonomía y medicina del trabajo. De la psicopatología a la psicodinámica del trabajo. Lumen, Buenos Aires, Argentina.

Dejours, Christophe (2000). "Psicodinámica del trabajo y vínculo social". Revista Actualidad Psicológica, pp. 274, 296.

Dejours, Christophe (2006). La banalización de la injusticia social. Topia, Buenos Aires, Argentina.

Dejours, Christophe (2009). El desgaste mental en el trabajo. Modus-Laborandis, Madrid, España.

Dejours, Christophe (2010). Contribución de la clínica del trabajo a la teoría del sufrimiento. Sitio Web de Revista Topia. Recuperado de:

https://www.topia.com.ar/articulos/contribuci\%C3\%B3n-cl\%C3\%ADnica-del-trabajoteor\% $3 \%$ AD-del-sufrimientohttp://www.topia.com.ar/articulos/contribuci\% $\%$ C $\%$ B3ncl\%C3\%ADnica-del-trabajo-teor\%C3\%AD-del-sufrimiento. (2010).

Dejours, Christophe (2012). Trabajo vivo: Sexualidad y trabajo. Tomo I. Topia, Buenos Aires, Argentina.

Dejours, Christophe (2013). Trabajo vivo: Trabajo y emancipación. Tomo II. Topia, Buenos 
Aires, Argentina.

Fernández, Eider (2013). Las que tienen que servir y las servidas: La evolución del servicio doméstico en el franquismo y la construcción de la subjetividad femenina. Revista Historia Autónoma, número 3, pp. 97-111.

Garduño, María y Márquez, Margarita (1995). El estrés en el perfil de desgaste de las trabajadoras. Cad. Saúde Públ, vol. 11, número 1, pp. 65-71.

Giddens, Anthony y Hutton, Will (2001). En el límite: La vida en el capitalismo global. Tusquets, Barcelona, España.

Gundermann, Hans. (2001). El método de los estudios de caso. En María Luisa Tarres (Coord.). Observar, escuchar y comprender. Sobre la tradición cualitativa en la investigación social .Miguel Ángel Porrúa - FLACSO, Ciudad de México, México, pp. 251-288.

Luhmann, Niklas (1992). Sociología del riesgo. UIA-UdeG, Guadalajara, México.

Martínez-Labrin, Soledad y Bivort-Urrutia, Bruno (2014). "Procesos de producción de subjetividad de género en el trabajo académico: Tiempos y espacios desde cuerpos femeninos". Psicoperspectivas: Individuo y Sociedad, vol. 13, número 1, pp. 15-22.

Meler, Irene (2012). "Construcción de la subjetividad y actitudes ante el trabajo: Diferencias y similitudes entre los género". Subjetividades y Procesos Cognitivos, vol, 16, número 2, pp. 70-94.

OIT-PSEM. (2015). Panorama social del empleo en el mundo. Ginebra: Autor., Suiza: OIT.

Rocha, Tania y Cruz, Cinthia (2013). "Barreras estructurales y subjetivas en la transición de mujeres mexicanas y su malestar emocional". Acta Colombiana de Psicología, vol. 16, número 1, pp. 123-135.

Sennett, Richard (2000). La corrosión del carácter. Anagrama, Barcelona, España.

Tarres, María Luisa (Coord.) (2001). Observar, escuchar y comprender. Sobre la tradición cualitativa en la investigación social. Miguel Ángel Porrúa -FLACSO, Ciudad de México, México.

Tunal, Gerardo. (2007). "Propuesta teórica para el estudio del mercado de trabajo femenino". Thoeria, vol. 16, número 1, pp. 46-61.

Vela-Peon, Fortino (2001). Un acto metodológico básico de investigación social: la entrevista cualitativa. En Tarres, María Luisa (Coord.). Observar, escuchar y comprender. Sobre la tradición cualitativa en la investigación social. Miguel Ángel Porrúa -FLACSO, Ciudad de México, México, pp. 63-95).

Vélez, Graciela (2009). "Conciliación entre la vida laboral y familiar de las mujeres: Un acuerdo pendiente". Asparkía, número 20, pp. 165-183. 
Yin, Robert (2004). Case study methods. American Educational Research Association, Washington, USA:

Revision of female labor subjectivity in Mexico from the Thesis of the Psychodynamics of Labor

\begin{abstract}
With the implementation of the neoliberal capitalist development model (80s), the global economic structure entered a phase of great transformations, which affected various developmental spaces. In the area of labor markets, the alterations impacted the typical configurations of employment, harming all the actors and thus disturbing their labor perceptions; From different levels of subjectivity. In the field of the subjectivity of work and having as object of study the women occupied in cleaning areas and based on the assumptions of the thesis of the psychodynamics of work (in the lines of new pathologies of work, evasion of Reality and family roles, and defense symbolism), the research identifies, analyzes and explains a series of (symbolic) strategies that have been instrumental in the development of its activities. These strategies aim to avoid the negative repercussions that the high levels of precariousness and inequality caused in their occupational, personal and family development, which apparently helped them to cope with their social life in an apparent harmony. Likewise, actions can contribute to perpetuate and sustain the exploitation traditionally suffered by this social stratum.
\end{abstract}

Keywords: Labor subjectivity. Women. Psychodynamics. Precariousness. Inequality

\title{
Revisão da subjetividade do trabalho feminino no México pela Tese Psicodinâmica do Trabalho
}

\section{Resumo}

Com a implementação do modelo de desenvolvimento capitalista neoliberal (80), a estrutura econômica global entrou em uma fase de grandes transformações que afetou diversos espaços de desenvolvimento. No campo dos mercados de trabalho, as alterações impactaram as configurações típicas do emprego, prejudicando todos os atores e perturbando suas percepções trabalhistas de diferentes níveis de subjetividade. No campo da subjetividade do trabalho e tendo como objeto de estudo as mulheres ocupadas nas áreas de limpeza e com base nos pressupostos da psicodinâmica do trabalho (nas linhas de novas patologias do trabalho, evasão de papéis de realidade e de família e simbolismo de defesa), a pesquisa identifica, analisa e explica uma série de estratégias (simbólicas) que contribuíram para 0 desenvolvimento de suas atividades. Essas estratégias visam evitar as repercussões negativas que os altos níveis de precariedade e de desigualdade causaram em seu desenvolvimento ocupacional, pessoal e familiar, o que aparentemente os ajudou a lidar com sua vida social em aparente harmonia. Do mesmo modo, as ações podem contribuir para perpetuar e sustentar a exploração tradicionalmente sofrida por este estrato social.

Palavras-chave: Subjetividade trabalhista. Mulheres. Psicodinâmica. Precariedade. Desigualdade. 